\title{
Goldenhar syndrome with left bronchopulmonary agenesis: A rare association
}

\author{
B. Ghimire, B. Thapa, U. K. Shrestha, P. Sayami \\ Cardio Thoracic and Vascular Unit, Department of Surgery, Tribhuvan University Teaching Hospital, Nepal. \\ Correspondence to: Bikal Ghimire, T.U.T.H, Kathmandu, Nepal.
}

Email:bikalghimire@gmail.com

\begin{abstract}
An eleven years female presented with recurrent chest infection since childhood with markedly diminished air entry on her right chest and mediastinal shift. She also had vague facial deformity with multiple auricular appendages. Computed tomography showed collapse of the left lung and on thoracotomy, complete agenesis of the left lung was noted. Goldenhar anomaly is rare and presents with variable degree of external anomaly. Its association with bronchopulmonary agenesis is extremely rare with few cases reported in the world literature. Features of other congenital should be sought for in a child with facial asymmetry, external auditory appendages, malformation of the, nose, soft palate, lip and mandible etc so that appropriate treatment can be administered.
\end{abstract}

\section{Introduction}

Goldenhar's syndrome is also known as the GoldenharGorlin syndrome (Maurice Goldenhar, Robert James Gorlin). ${ }^{1}$ It presents with variable features but the consistent findings are, hemifacial microsomia, weakness of the muscles of mouth and teeth, dermoid in the eye, some degree of hearing loss, external auditory appendages etc. ${ }^{1,2}$ Patients may also have skeletal, cardiac, renal and CNS abnormality. It is more common in the males $(70 \%)$.

\section{Case report}

Our patient was an 11 year old female suffering from recurrent bouts of chest infection treated with medications since childhood. She suffered from low grade, intermittent fever with occasional shortness of breath and unproductive cough. On examination, she had slight deformity of the face with deviation to the left and multiple ear appendages (Fig. $1,2)$. She had high arched palate with moderate hearing loss on her left ear.

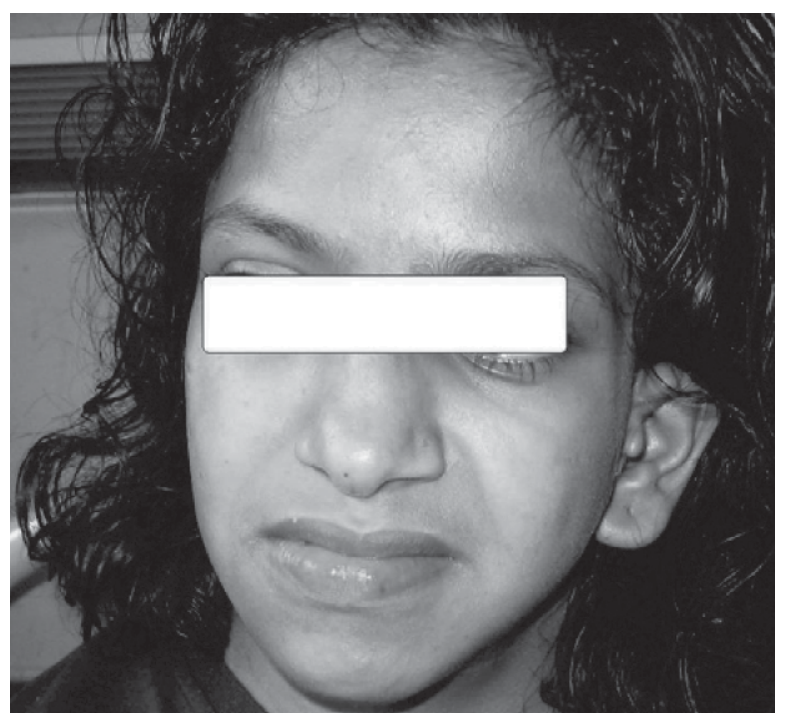

Fig. 1: Slight deformity of the face with mandibular hypoplasia on the left side 


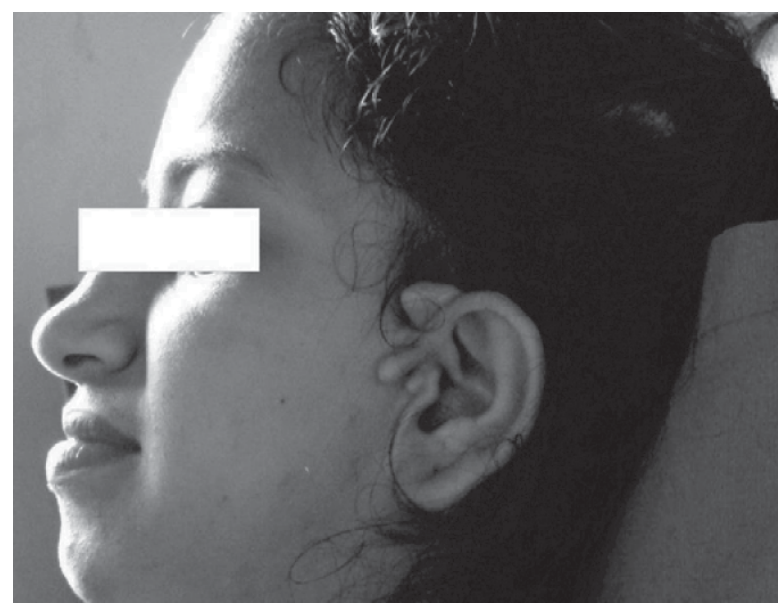

Fig. 2: Auricular appendages

The trachea was deviated to the left with diminished air entry on that side. Computed tomography scan of her chest showed collapsed left lung with gross mediastinal shift to the left, crowing of ribs and tracheal shift to the left. The Lobar bronchus was not visualized but the right lung was hyper inflated. With the impression of left lung collapse, she underwent left thoracotomy. The operative findings noted were, complete agenesis of left lung with a short left bronchial stump and a large thymus gland. Extensive literature review and correlation of her facial abnormalities finally led us to conclude it as a rare case of left 'Bronchopulmonary agenesis' with 'Goldenhar anomaly'. On further investigations, she did not have any cardiac or vertebral anomalies. On examination of the eye, there were no epibulbar dermoids and there was no evidence of mental retardation. The pregnancy and delivery were normal and the mother also had not taken any teratogens during her pregnancy.

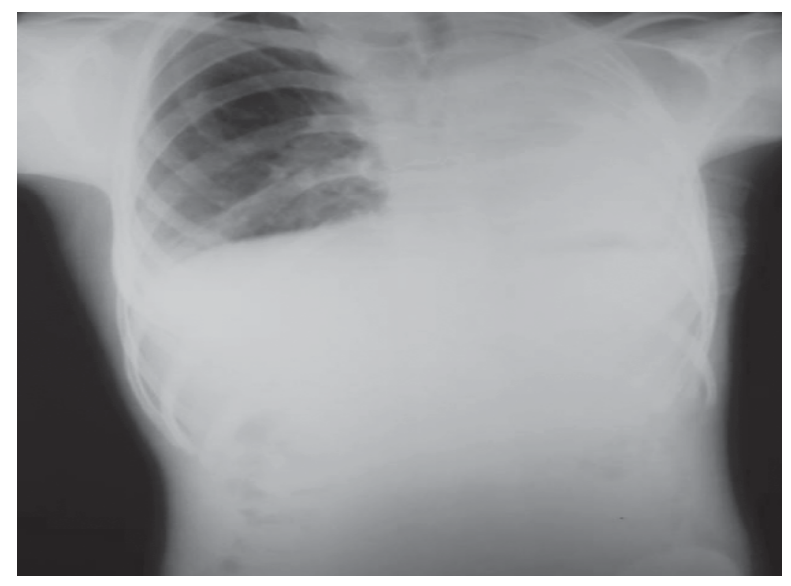

Fig. 3: Chest $\mathrm{X}$-ray showing tracheal deviation

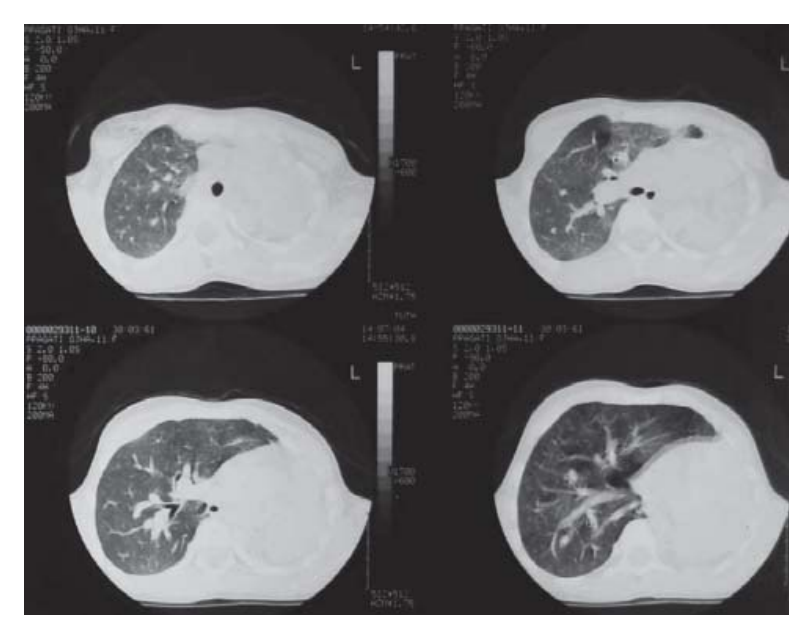

Fig. 4: CT scan of the chest with gross mediastinal shift

\section{Discussion}

Goldenhar syndrome is also known as oculoauriculovertebral spectrum or OAV syndrome. It has variable presentation and involves malformation of the external ear, nose, soft palate, lip and mandible etc but is usually asymmetrical hence it is also called hemifacial microsomia specially if there is no other internal organ involvement. ${ }^{3}$ The defect involves structures arising from the first and second branchial arches, the first branchial pouch, the first branchial cleft and the primodia of the temporal bone. ${ }^{4}$

The diagnosis of this condition is controversial due to varied clinical presentations. ${ }^{5}$ There has been a few reports of pulmonary agenesis and goldenhar syndrome in the literature. ${ }^{6,7,8,9}$ When pulmonary agenesis is associated with Goldenhar syndrome, it is referred as an expanded Goldenhar complex. Most of the case reports have been of infants. Our patient exhibited microtia with peri-auricular appendices and facial asymmetry which is considered a typical feature. ${ }^{10}$ Cleft lip is observed in 5\% of the cases and the frequency of cardiovascular anomaly ranges from 5 to $58 \%$ but our patient had a high arched palate with no evidence of cleft lip or any cardiovascular anomaly. ${ }^{11,12}$

In our patient there was no familial occurrence and the mother also had not taken any medication during pregnancy. Though two neighboring microdeletions of 5q13.2 were reported in a patient with Goldenhar syndrome, no definite genetic origin has been identified. ${ }^{13}$ Goldenhar's syndrome may be a sporadic event occurring early in the embryogenesis.

Pulmonary agenesis has been reported in patients with Goldenhar syndrome and most of them are unilateral. ${ }^{9}$ Most 
of these patients suffer from respiratory distress in the neonatal period. Our patient was diagnosed with the anomaly very late and was being treated for recurrent chest infection.

\section{Conclusion}

Any child with facial asymmetry, external auditory appendages, malformation of the, nose, soft palate, lip and mandible etc should be investigated for other associated congenital malformations of the internal organs so that they can be managed early.

\section{References}

1. Goldenhar M. Associations malformatives do I'oeil et de I' oreille, enn partiaulier le syndrome dermoide epidbulbaue - ependices auricularies - fistula auris congenital et ses relations avec la dysostose mandibulo-facile. J Genet Hum 1952; 1: 243-282.

2. Kita D, Munemoto S, Ueno Y, Fukuda A. Goldenhar"s syndrome associated with occipital meningoencephalocele - case report. Neurol Med Chir (Tokyo) 2002;42 (8):354-5

3. Ermis B, Oztas N, Yildirim M, Hosnuter M, Yavuz T. Pulmonary hypoplasia in a newborn with Goldenhar syndrome. J Pediatr. 2010 Jan; 156(1):161.

4. Langman's Medical embryology, 6th edn. Baltimore, Williams and Wilkins, 1979; pp 297-327.

5. Pinheiro BAL, Araujo L C, Oliveira SB, Sampaio MCC, Freitas AC. Goldenhar's syndrome-case report. Braz Dent J (2003) 14(1): 67-70

6. Downing GJ, Kilbride H. An interesting case presentation: pulmonary malformations associated with oculoauriculovertebral dysplasia (Goldenhar anomalad). J Perinatol. 1991;11:190-192

7. Maymon R, Schneider D, Hegesh J, Herman A, Weinraub Z, Achiron R. Antenatal sonographic findings of right pulmonary agenesis with ipsilateral microtia: a possible new laterality association. Prenat Diagn. 2001;21:125-128

8. Milani D, Selicorni A. Right pulmonary agenesis with ipsilateral microtia: a new laterality association or part of the oculoauriculovertebral spectrum?. Prenat Diagn. 2002;22:1053-1054

9. Greenough A, Ahmed T, Broughton S. Unilateral pulmonary agenesis. J Perinat Med 2006;34:80-1
10. Schaffer AJ, Avery ME. Doenças do Recém-Nascido. 4th ed. São Paulo: Interamericana; 1979. p 803

11. Oski FA, de Angelis CA, Feigin RD, Warshaw JB. Síndromes comuns com anormalidades morfológicas. Princípios e Prática de Pediatria. Rio de Janeiro: Guanabara Koogan; 1990. p 482

12. Nakajima H, Goto G, Nakata N. Goldenhar syndrome associated with various cardiovascular malformations. Jnp Circ J. 1998;62:617-620

13. Huang XS, Xiao L, Li X, Xie Y, Jiang HO, Tan C et al. Two neighboring microdeletions of 5 q13.2 in a child with oculo-auriculo-vertebral spectrum. Eur J Med Genet. 2010 May-Jun;53(3):153-8. Epub 2010 Mar 24. 